\title{
Neuroprotective effect of dapsone in patients with aneurysmal subarachnoid hemorrhage: a prospective, randomized, double-blind, placebo-controlled clinical trial
}

\author{
Cuauhtémoc García-Pastor, MD, ${ }^{1}$ Juan P. Navarro-Garcia de Llano, MD, ${ }^{1}$ \\ Juan C. Balcázar-Padrón, MD, ${ }^{1}$ Luis Tristán-López, PhD, ${ }^{2}$ Camilo Rios, PhD, ${ }^{2}$ \\ Araceli Díaz-Ruíz, MD, ${ }^{2}$ Luis A. Rodríguez-Hernandez, MD, ${ }^{1}$ and Edgar Nathal, MD1
}

${ }^{1}$ Neurosurgery Department and ${ }^{2}$ Neurochemistry Department, Instituto Nacional de Neurología y Neurocirugía "Manuel Velasco Suárez," Mexico City, Mexico

OBJECTIVE In this study, the authors sought to define the differences in the incidence of delayed cerebral ischemia (DCl) between patients treated with dapsone and those treated with placebo. Secondary objectives were to define the clinical outcome at discharge and 3 months and the incidence of brain infarction.

METHODS A prospective, randomized, double-blind, placebo-controlled study was performed and included patients with aneurysmal subarachnoid hemorrhage (SAH) within 5 days from ictus who were candidates for aneurysm occlusion, and who had a Fisher grade of 3 or 4 . Patients with sulfa or sulfone drug allergies, hemoglobin $<11 \mathrm{~g} / \mathrm{dl}$, known G6PD deficiency, and those refusing informed consent were excluded. A minimal relevant effect decrease of $35 \%$ in the incidence of $\mathrm{DCl}$ was established. Patients were randomly assigned to receive a regimen of dapsone $2.5 \mathrm{ml}(100 \mathrm{mg})$ daily or a placebo (aluminum hydroxide suspension, $2.5 \mathrm{ml}$ daily). Both groups received validated treatment for aneurysmal SAH. The appearance of $\mathrm{DCl}$ on CT was assessed in every patient at discharge and 3 months later. We used the chi-square test to compare the $\mathrm{DCl}$ incidence between both groups, and the Student t-test or nonparametric tests to compare quantitative variables.

RESULTS Overall, 48 patients (70.8\% women and $29.2 \%$ men) were included. The mean age was 50 years (SD 14.28 years, range 18-72 years). Prerandomization and postrandomization characteristics were balanced, except for the necessity of intra-arterial nimodipine administration in patients treated with placebo $(15.4 \% \mathrm{vs} 45.5 \%, p=0.029$. The incidence of $\mathrm{DCl}$, the primary endpoint, for the whole cohort was $43.8 \%$ and was significantly lower in the dapsone group $(26.9 \%$ vs $63.6 \%, p=0.011)$. In addition, the irreversible $\mathrm{DCl}$ incidence was lower in the dapsone group ( $11.5 \%$ vs $54.5 \%, p=0.12)$. A favorable modified Rankin Scale score was more frequent in the dapsone group at discharge and at 3 months $(76.9 \%$ vs $36.4 \%, p=0.005$ and $80 \%$ vs $38.9 \%, p=0.019$, respectively). Also, the brain infarction incidence was lower in the dapsone group (19.2\% vs $63.6 \%, p=0.001)$. There was no difference between groups regarding adverse events.

CONCLUSIONS Dapsone seems to play a role as a prophylactic agent in patients at high risk of developing $\mathrm{DCl}$ after aneurysmal SAH. A multicenter investigation is necessary to increase the study population and confirm the consistency of the results observed in this study.

Clinical trial registration no.: NCT05131295 (clinicaltrials.gov)

https://thejns.org/doi/abs/10.3171/2021.12.FOCUS21663

KEYWORDS dapsone; cerebral vasospasm; delayed cerebral ischemia; subarachnoid hemorrhage; aneurysms; neuroprotective effect

$\mathrm{S}$ UBARACHNOID hemorrhage (SAH) represents $8 \%$ to $15 \%$ of all cerebrovascular diseases. It has been reported that vasospasm is found on angiography in $50 \%$ to $70 \%$ of patients with SAH. ${ }^{1}$ Moreover, $19 \%$ to $46 \%$ of these patients present with delayed cerebral ischemia
(DCI) ${ }^{2-4}$ Rebleeding and DCI are the main causes of morbidity and mortality in patients with aneurysmal SAH, and as early surgery has become the standard of treatment to prevent rebleeding, DCI is now the principal prognostic factor. $^{5-9}$ Until now, even when the pathophysiology has

ABBREVIATIONS $\mathrm{DCl}=$ delayed cerebral ischemia; $\mathrm{mRS}$ = modified Rankin Scale; $\mathrm{SAH}=$ subarachnoid hemorrhage . ACCOMPANYING EDITORIAL DOI: 10.3171/2021.12.FOCUS21774.

SUBMITTED October 31, 2021. ACCEPTED December 10, 2021.

INCLUDE WHEN CITING DOI: 10.3171/2021.12.FOCUS21663. 
not been fully understood, several risk factors for the development of DCI have been identified, and the amount of subarachnoid blood observed on CT remains the most consistent predictive factor of DCI. ${ }^{5,7,10,11}$ Other commonly cited factors with some caveats are neurological grade on admission, advanced age, ${ }^{7,12}$ white blood cell count, ${ }^{2}$ glucose level, arterial hypertension, and aneurysm treatment modality. ${ }^{7} 13-17$

Given the devastating effects of DCI, multiple treatments have been investigated in its prevention, from physical maneuvers such as washing the subarachnoid space to molecular interventions; ${ }^{18,19}$ however, few drugs have proven to be effective in the clinical setting. Currently, only oral nimodipine has proven efficacy for the prevention and treatment of cerebral vasospasm. ${ }^{20,21}$

Dapsone is a drug that has been used clinically for several decades because of its anti-infective effect; it is the drug of choice to treat leprosy and is accepted in the prophylaxis of Pneumocystis pneumonia and cerebral toxoplasmosis in patients who are HIV positive. It also has an anti-inflammatory effect due to its inhibitory action on neutrophils, which has led to its use in neutrophilic dermatosis and as an optional treatment in many other noninfectious conditions. ${ }^{22-26}$

Neuroprotective effects have been found experimentally with the use of dapsone, predominantly through its glutamate receptors' antagonistic effect; these are the main receptors involved in neuronal excitotoxicity. Under this hypothesis, an antiepileptic effect has been demonstrated in experimental animals, reducing the destruction induced by kainic acid ${ }^{27}$ and showing protective effects in acute spinal injury or focal ischemic damage ${ }^{17}$ Clinically, a protective effect has been shown in ischemic vascular disease of atherothrombotic origin.

Our main objective was to study the neuroprotective properties of dapsone in patients with aneurysmal SAH and high-risk factors for the development of cerebral vasospasm and DCI.

\section{Methods \\ Patients}

Between September 5, 2007, to December 7, 2008, eligible adult patients were enrolled in a prospective, randomized, double-blind, placebo-controlled study at the Instituto Nacional de Neurología y Neurocirugía "Manuel Velasco Suárez" in Mexico City. The patient population included those presenting with aneurysmal SAH, defined as the presence of sudden neurological symptoms, meningeal syndrome on examination, evidence of SAH on CT, and documentation of an aneurysm by digital angiography. The clinical research department and bioethics committee of the institution approved the study. In addition, informed consent was obtained from all included patients, and the study was successfully registered (registration no. NCT05131295, ClinicalTrials.gov).

\section{Treatment Allocation}

Using a computer-derived table, patients were randomly assigned to receive a $2.5-\mathrm{ml}$ oral dose of the placebo every 24 hours (aluminum hydroxide suspension) or a dapsone suspension containing $100 \mathrm{mg}(2.5 \mathrm{ml}$ every 24 hours). In patients with impaired consciousness, a nasogastric tube was used. Treatment was initiated during the first 5 days postictus and continued until day 15. All patients underwent aneurysm clipping by microsurgery or an endovascular procedure. Postoperatively, both groups received the usual prophylaxis (which included oral nimodipine from admission until day 21 postictus, normovolemia, and dextran) and/or treatment (which included the use of vasogenic amines and, in refractory cases, cerebral intra-arterial administration of nimodipine) of cerebral vasospasm. Patients, investigators, and clinical assessment staff were blinded to treatment assignments throughout the research process. The institution's neurochemistry laboratory provided both the placebo and dapsone.

\section{Exclusion Criteria}

Patients were excluded if they had known glucose6-phosphate dehydrogenase (G6PD) deficiency, anemia at admission, allergy to sulfones or sulfas, or severe systemic disease (renal or hepatic failure). Once admitted to the study, patients who decided not to continue in the study and those in whom it was not possible to secure or embolize the aneurysm responsible for the event were excluded.

\section{Evaluation of Patients}

Prerandomization clinical characteristics were assessed in both groups. On admission to the hospital and after confirming the presence of SAH by $\mathrm{CT}$, the clinical severity of the event was classified by the World Federation of Neurosurgical Societies grading system, ${ }^{28}$ and the amount of subarachnoid blood on the first CT scan at admission was classified according to the original Fisher scale as follows: grade 1, none; grade 2, diffuse only; grade 3, clot or thick layer; and grade 4, diffuse or none, with cerebral or ventricular blood. ${ }^{29}$ All patients were followed up during their stay to evaluate for the appearance of DCI, its clinical expression, and whether it was reversible or irreversible. After discharge, patients were followed up for at least 3 months, during which time their clinical outcome was assessed using the modified Rankin Scale (mRS). The appearance of severe adverse events, such as methemoglobinemia, and other less severe effects, such as skin reactions that forced treatment discontinuation, were also assessed.

\section{Primary Endpoint and Secondary Outcomes}

The predetermined primary endpoint was the incidence of clinically defined DCI. The predetermined secondary outcome variables were clinical outcome at discharge and 3 months later, and the infarction incidence as demonstrated by CT.

\section{Definition of Outcome Variables}

DCI was defined as the development of focal neurological deficits or impaired consciousness with progression to stupor or coma. DCI was classified as 1) reversible, if the deficit reversed with the treatment used for cerebral vasospasm; and 2) irreversible, if there was no response to treatment and a persistent deficit occurred. Other possible 
TABLE 1. Patient characteristics prerandomization

\begin{tabular}{|c|c|c|c|c|}
\hline Variable & Total $(n=48)$ & Dapsone Group $(n=26)$ & Placebo Group ( $n=22$ ) & p Value \\
\hline Sex & & & & 0.103 \\
\hline $\mathrm{F}$ & $34(70.8)$ & $16(61.5)$ & $18(81.8)$ & \\
\hline M & $14(29.2)$ & $10(38.5)$ & $4(18.2)$ & \\
\hline Mean age, yrs (SD) & $50(14.28)$ & $50.15(1.9)$ & $49.8(12.5)$ & 0.937 \\
\hline Chronic hypertension & $26(54.2)$ & $15(57.7)$ & $11(50)$ & 0.594 \\
\hline Diabetes mellitus & $3(6.25)$ & $3(11.5)$ & 0 & 0.133 \\
\hline Mean initial glucose, mg/dl (SD) & $127.87(45.55)$ & $128.48(54.9)$ & $127.18(33.00)$ & 0.502 \\
\hline Mean initial WBC count, cells per mm³ (SD) & $12,069(3971)$ & $11,534.40(3887.2)$ & $12,677(4068.5)$ & 0.330 \\
\hline Smoking & $17(35.4)$ & $9(34.6)$ & $8(36.4)$ & 0.900 \\
\hline Cocaine use & $2(4.2)$ & $2(7.7)$ & 0 & 0.184 \\
\hline WFNS grade & & & & 0.546 \\
\hline II & $33(68.8)$ & $19(73.1)$ & $14(63.6)$ & \\
\hline III & $9(18.8)$ & $5(19.2)$ & 4 (18.2) & \\
\hline IV & $6(12.5)$ & $2(7.7)$ & $4(18.2)$ & \\
\hline Fisher grade & & & & 0.682 \\
\hline 3 & $32(66.7)$ & $18(69.2)$ & $14(63.6)$ & \\
\hline 4 & $16(33.3)$ & $8(30.8)$ & $8(36.4)$ & \\
\hline Vasospasm on initial angiography & $18(37.5)$ & $8(30.8)$ & $10(45.5)$ & 0.295 \\
\hline Aneurysm location & & & & 0.242 \\
\hline $\mathrm{ACoA}$ & $11(22.9)$ & $9(34.6)$ & $2(9.1)$ & \\
\hline MCA & $13(27.1)$ & $7(26.9)$ & $6(27.3)$ & \\
\hline ICA (posterior communicating segment) & $13(27.1)$ & $5(19.2)$ & $8(36.4)$ & \\
\hline ICA (not including posterior communicating segment) & $5(10.4)$ & $1(3.8)$ & 4 (18.2) & \\
\hline VB junction & $1(2.1)$ & 0 & $1(4.5)$ & \\
\hline Other & $5(10.4)$ & $4(15.4)$ & $1(4.5)$ & \\
\hline
\end{tabular}

$\mathrm{ACOA}=$ anterior communicating artery; ICA = internal carotid artery; MCA = middle cerebral artery; VB = vertebrobasilar; WBC = white blood count; WFNS = World Federation of Neurosurgical Societies.

Values represent the number of patients (\%) unless indicated otherwise.

complications that could be responsible for the deficit (hydrocephalus, rebleeding, surgical complications, infection, or metabolic alterations) were ruled out by repeat imaging (CT, MRI, or cerebral pan-angiography) and metabolic blood analysis. The immediate postoperative deficit was defined as a new neurological deficit that would be evident immediately after recovery from anesthesia. Cerebral infarction was defined as the appearance of a new localized hypodensity in a vascular distribution in the final CT scan prior to discharge; we used validated arterial territory maps for this purpose. ${ }^{30}$ Clinical outcome was defined by the patient's mRS score at discharge and 3 months after; a favorable outcome was defined as an mRS score $\leq 2$ and unfavorable as an $\mathrm{mRS}$ score $\geq 3$.

\section{Statistical Analysis}

Data were analyzed according to a defined prospective plan. The primary endpoint was the incidence of DCI dur-

TABLE 2. Patient characteristics postrandomization

\begin{tabular}{lccrc}
\hline \multicolumn{1}{c}{ Variable } & Total $(\mathrm{n}=48)$ & Dapsone Group $(\mathrm{n}=26)$ & Placebo Group $(\mathrm{n}=22)$ & $\mathrm{p}$ Value \\
\hline Immediate postop deficit & $5(10.4)$ & $1(3.8)$ & $4(18.2)$ & 0.165 \\
\hline Mean time of temporary clipping, mins (SD) & $6.83(9.2)$ & $5.7(5.5)$ & $8.32(12.7)$ & 0.981 \\
\hline Mean interval from ictus to drug initiation, days (SD) & $3.85(1.3)$ & $4(1.3)$ & $3.6(1.2)$ & 0.479 \\
\hline Type of occlusion & & & & 0.320 \\
\hline Microsurgery & $44(91.7)$ & $25(96.2)$ & $19(86.4)$ & \\
\hline Embolization & $4(8.3)$ & $1(3.8)$ & $3(13.6)$ & \\
\hline Intra-arterial nimodipine & $14(29.2)$ & $4(15.4)$ & $10(45.5)$ & 0.029 \\
\hline
\end{tabular}

Values represent the number of patients (\%) unless indicated otherwise. Boldface type indicates statistical significance. 
TABLE 3. Primary endpoint

\begin{tabular}{rrrcc}
\hline & \multicolumn{3}{c}{ No. of Patients (\%) } & \\
\cline { 2 - 4 } Variable & Total & Dapsone Group & Placebo Group & p Value \\
\hline DCl incidence & $21(43.8)$ & $7(26.9)$ & $14(63.6)$ & 0.011 \\
\hline Reversible & $6(12.5)$ & $4(15.4)$ & $2(9.1)$ & 0.120 \\
\hline Irreversible & $15(31.3)$ & $3(11.5)$ & $12(54.5)$ & \\
\hline
\end{tabular}

Boldface type indicates statistical significance.

ing the first 21 days post-SAH. The clinical outcome at 3 months and the presence of infarction on CT at patient discharge were analyzed as secondary outcomes.

The projected sample size was 50 patients, guaranteeing a power of $80 \%$ (error $\beta$ 0.2) to detect a statistically significant difference between placebo and dapsone treatment, with an accepted two-tailed $\alpha$ error of 0.05 . The sample size was calculated assuming an incidence of DCI of $45 \%$ in the placebo group and $10 \%$ in the dapsone group, making a difference of $35 \%$ between groups.

We present categorical variable data as incidences and compare groups using the chi-square test or Fisher's exact test (when any of the cells had $<5$ patients). Continuous variables are presented as mean and standard deviation (SD). The statistical test for these variables was the Student t-test or nonparametric tests such as the Mann-Whitney U-test. We established statistical significance with a $\mathrm{p}$ value $<0.05$ and used IBM SPSS Statistics version 23.0 (IBM Corp.) to perform the analysis.

\section{Results}

\section{Recruitment of Patients}

A total of 256 patients were assessed for the study. Of these, 175 did not meet the inclusion criteria, and 32 did not choose to participate. Initially, 49 patients were included in the study; however, 1 patient assigned to the placebo group voluntarily retired, leaving a total of 48 patients for the final analysis, of whom 26 corresponded to the dapsone group and 22 to the placebo group. The mean age for the entire cohort was 50 years (SD 14.28 years, range 18-72 years). The mean time between the ictus and the start of treatment was 3.85 days (SD 1.3 days, range 1-5 days). The overall mortality was $16.7 \%$ (8 patients died).

\section{Patient Characteristics}

Pre- and postrandomization characteristics were balanced between the two groups, and no statistically significant differences were shown (Tables 1 and 2), except for the need for intra-arterial nimodipine administration, which was lower in the dapsone group (15.4\% vs $45.5 \%$, $\mathrm{p}=0.029)$.

\section{Primary Endpoint}

The primary endpoint analysis yielded a statistically significant reduction in the incidence of DCI in the group of patients who received dapsone compared with those who received placebo $(26.9 \%$ vs $63.6 \%, \mathrm{p}=0.011)$ (Table 3 and Fig. 1). Additionally, a reduction was observed in the incidence of irreversible DCI, which was lower in the dapsone group, without reaching a statistically significant difference $(11.5 \%$ vs $54.5 \%, \mathrm{p}=0.120)$ (Fig. 2 ).

\section{Secondary Outcomes}

At discharge, patients who received dapsone had favorable mRS scores compared with those who received the placebo $(76.9 \%$ vs $36.4 \%, \mathrm{p}=0.005)$. The same result was observed in the assessment at 3 months $(80 \%$ vs $38.9 \%$, $\mathrm{p}=0.019$ ) (Fig. 3). The incidence of ischemic stroke detected by $\mathrm{CT}$ showed a significant difference favoring the dapsone group $(19.2 \%$ vs $63.6 \%, p=0.001)$ (Table 4$)$.

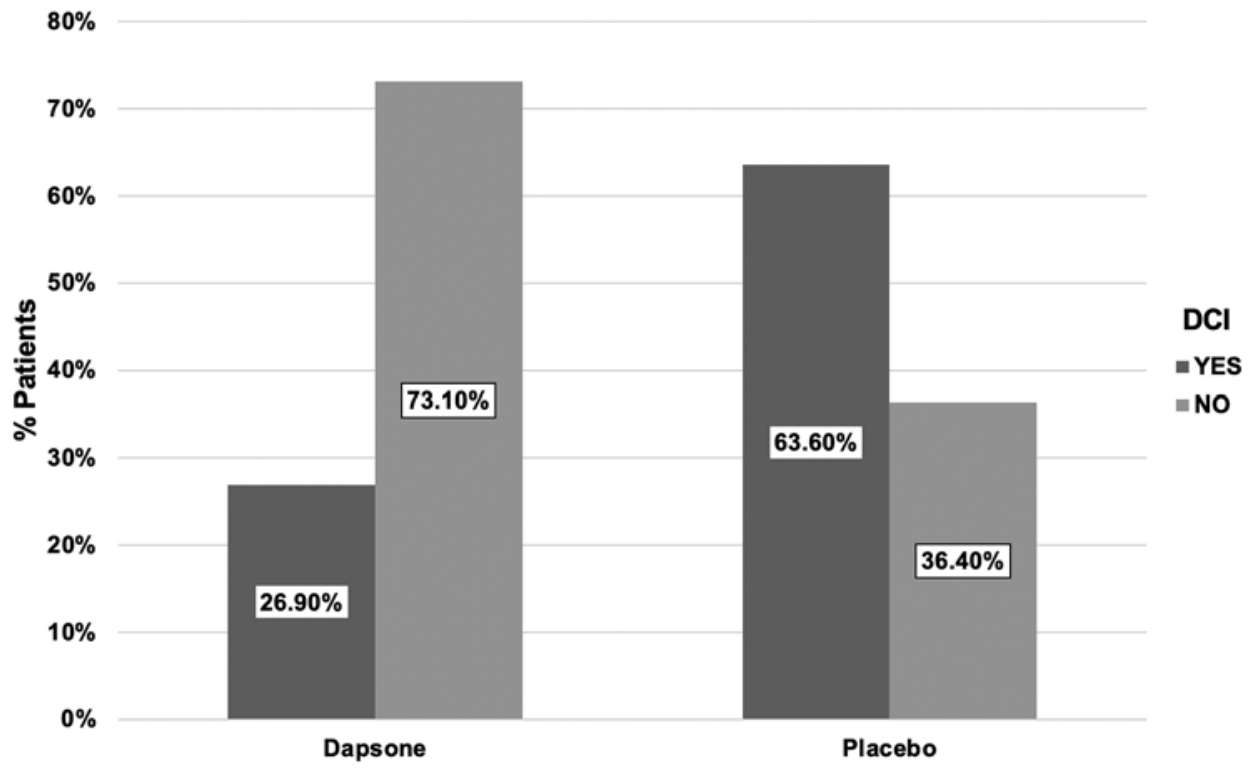

FIG. 1. Bar graph showing the incidence of $\mathrm{DCl}$. 


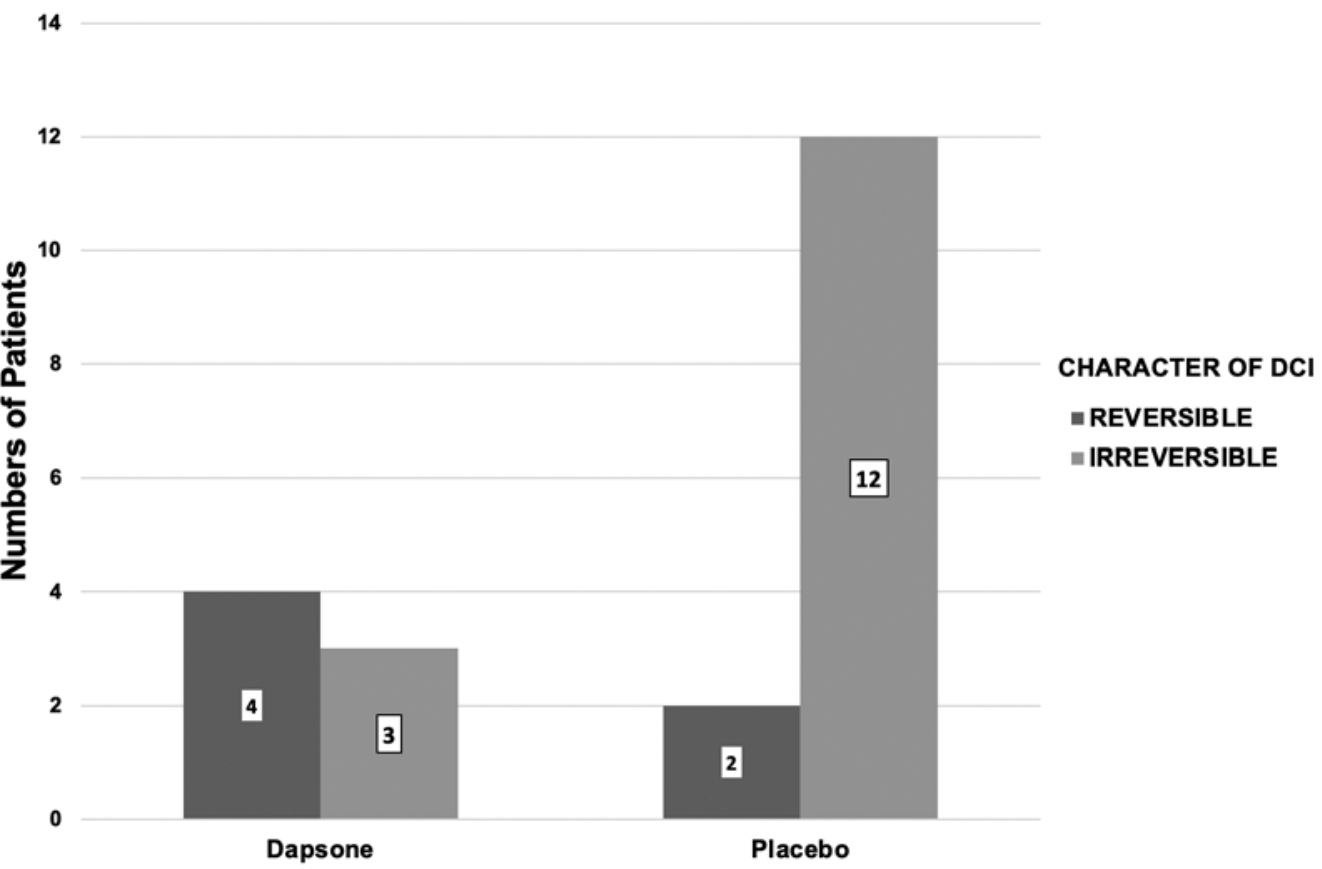

FIG. 2. Bar graph showing DCI character (reversible vs irreversible).

\section{Collateral Effects}

No patient had serious collateral effects; thus, no drug suspension was required and no statistically significant differences were observed between groups regarding these effects $(22 \%$ vs $15 \%, \mathrm{p}=0.710)$.

\section{Discussion}

This is the first study to suggest a clinical effect of dapsone as a neuroprotective agent in SAH. There are already reports of its neuroprotective effect in experimental epilepsy models,,${ }^{27}$ ischemia,${ }^{17}$ and clinical efficacy in atherothrombotic infarction (Table 5).

In this study, a statistically significant reduction in the incidence of reversible and irreversible DCI was shown in patients who were assigned to receive dapsone compared with those who received placebo. We decided to use DCI as the primary endpoint in this study, and not Doppler ultrasonography or angiographic vasospasm, for two fundamental reasons. 1) We believe that the effect of dapsone is

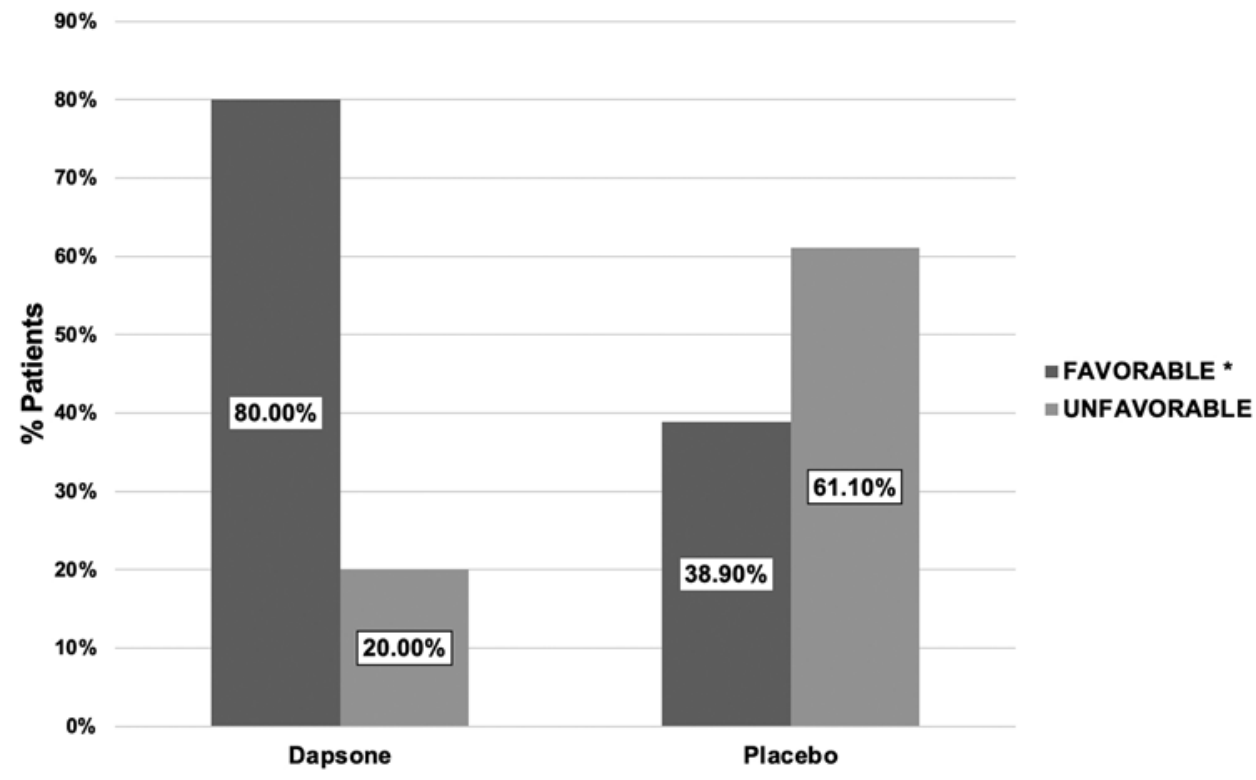

FIG. 3. Bar graph showing mRS scores at 3 months. ${ }^{*} A n$ mRS score $\leq 2$ is considered favorable. 
TABLE 4. Secondary outcomes

\begin{tabular}{lcccc}
\hline \multicolumn{1}{c}{ Variable } & $\begin{array}{c}\text { Total, } \mathrm{n} \\
(\%)\end{array}$ & $\begin{array}{c}\text { Dapsone, } \\
\mathrm{n}(\%)\end{array}$ & $\begin{array}{c}\text { Placebo, } \\
\mathrm{n}(\%)\end{array}$ & $\begin{array}{c}\mathrm{p} \\
\text { Value }\end{array}$ \\
\hline mRS score* at discharge & & & & 0.005 \\
\hline Good & $28(58.3)$ & $20(76.9)$ & $8(36.4)$ & \\
\hline Poor & $20(41.7)$ & $6(23.1)$ & $14(63.6)$ & \\
\hline mRS score at 3 mos & & & 0.019 \\
\hline$\quad$ Good & $23(60.5)$ & $16(80)$ & $7(38.9)$ & \\
\hline Poor & $15(39.5)$ & $4(20)$ & $11(61.1)$ & \\
\hline $\begin{array}{l}\text { Death } \\
\text { Brain infarction on CT }\end{array}$ & $8(16.7)$ & $2(7.7)$ & $6(27.3)$ & 0.058 \\
\hline * Considering good outcome as an mRS score 0-2 and poor outcome as an \\
mRS score $\geq 3$.
\end{tabular}

to protect ischemic brain tissue and not to avoid the cerebral vasospasm phenomenon. 2) Additionally, it has been documented that cerebral ischemia can occur in patients post-SAH who do not present vasospasm on transcranial Doppler ultrasonography or angiography. ${ }^{31,32}$

Despite not having achieved a 35\% reduction in the overall incidence of DCI, the difference between the two groups was statistically significant, favoring dapsone. On the other hand, if we consider the incidence of irreversible DCI in isolation, the difference is even greater and reaches a reduction of $35 \%$ between groups. These two phenomena, in addition to the fact that the placebo group showed an increased need for intra-arterial cerebral nimodipine, make us think that the main role of dapsone is the protection of ischemic brain tissue and that its usefulness may be added to other modalities in the treatment of vasospasm associated with aneurysmal SAH.

It is important to note that the incidence of DCI, in general, is relatively high (43.8\%), being even higher for the placebo group (63.6\%). This can be explained by the fact that the cohort represents a subpopulation of patients with SAH and high-risk factors for the development of DCI. The incidence of DCI and clinical outcome is comparable with studies where other drugs have shown some effect in the prevention and treatment of DCI.

In addition, dapsone showed statistically significant differences in the improvement of the clinical outcome at discharge and at 3 months, as well as reduction in the number of cerebral infarcts related to SAH. In this sense, the outcome is as expected if we consider that DCI is the main determinant of the clinical and infarct outcome in patients with aneurysmal SAH. ${ }^{33,34}$ The overall incidence of stroke detection by CT for the whole cohort is at the upper limit of what has been previously reported $;{ }^{33}$ however, it is higher in the placebo group.

The neuroprotective effect of dapsone may be due to two previously tested mechanisms. The first is by avoid-

TABLE 5. Cerebral vasospasm clinical trials found in the literature

\begin{tabular}{|c|c|c|c|c|c|c|}
\hline \multirow{2}{*}{$\begin{array}{l}\text { Authors } \\
\& \text { Year }\end{array}$} & \multirow[b]{2}{*}{ Drug } & \multirow{2}{*}{$\begin{array}{l}\text { No. of } \\
\text { Pts }\end{array}$} & \multirow[b]{2}{*}{ Multicenter } & \multirow{2}{*}{$\begin{array}{c}\text { DCI Incidence } \\
(\%)\end{array}$} & \multicolumn{2}{|c|}{ Clinical Outcome } \\
\hline & & & & & Favorable (\%) & Unfavorable (\%) \\
\hline \multirow{2}{*}{$\begin{array}{l}\text { Mee et al., } \\
1988^{36}\end{array}$} & Nimodipine & 25 & \multirow{2}{*}{ No } & \multirow{2}{*}{$\mathrm{NP}$} & 76 & 20 \\
\hline & Placebo & 25 & & & 52 & 48 \\
\hline \multirow{2}{*}{$\begin{array}{l}\text { Ohman \& Heis- } \\
\text { kanen, } 1988^{37}\end{array}$} & Nimodipine & 104 & \multirow{2}{*}{ No } & \multirow{2}{*}{ NP } & 90.3 & 9.7 \\
\hline & Placebo & 109 & & & 80.0 & 20 \\
\hline \multirow{2}{*}{$\begin{array}{l}\text { Petruk et al., } \\
1988^{38}\end{array}$} & Nimodipine & 72 & \multirow{2}{*}{ Yes } & 45.8 & 26.4 & 73.6 \\
\hline & Placebo & 82 & & 65.9 & 18.3 & 81.7 \\
\hline \multirow{2}{*}{$\begin{array}{l}\text { Pickard et al., } \\
1989^{39}\end{array}$} & Nimodipine & 278 & \multirow{2}{*}{ Yes } & 22 & 80 & 20 \\
\hline & Placebo & 276 & & 33 & 67 & 33 \\
\hline \multirow{2}{*}{$\begin{array}{l}\text { Asano et al., } \\
1996^{40}\end{array}$} & Nicaraven & 74 & \multirow{2}{*}{ Yes } & 35.5 & 63.8 & 36.2 \\
\hline & Placebo & 73 & & 54.2 & 43.9 & 56.1 \\
\hline \multirow{3}{*}{$\begin{array}{l}\text { Haley et al., } \\
1997^{41}\end{array}$} & Tirilazad $2^{*}$ & 298 & \multirow{3}{*}{ Yes } & 30 & 68 & 32 \\
\hline & Tirilazad 6* & 299 & & 33 & 72 & 28 \\
\hline & Placebo & 300 & & 33 & 73 & 27 \\
\hline \multirow{2}{*}{$\begin{array}{l}\text { Zhao et al., } \\
2011^{42}\end{array}$} & Fasudil & 55 & \multirow{2}{*}{ Yes } & 14.3 & 74.5 & 25.5 \\
\hline & Nimodipine & 60 & & 24.1 & 61.7 & 38.3 \\
\hline \multirow{2}{*}{$\begin{array}{l}\text { Matsuda et al., } \\
2016^{43}\end{array}$} & Cilostazol & 74 & \multirow{2}{*}{ Yes } & 11 & 94.6 & 5.4 \\
\hline & Placebo & 74 & & 24 & 82.4 & 17.6 \\
\hline \multirow{2}{*}{$\begin{array}{l}\text { Chen et al., } \\
2020^{44}\end{array}$} & Atorvastatin & 150 & \multirow{2}{*}{ Yes } & 18.7 & 54 & 46 \\
\hline & Placebo & 150 & & 24.7 & 48.7 & 51.3 \\
\hline \multirow[t]{2}{*}{ Present study } & Dapsone & 26 & \multirow{2}{*}{ No } & 26.9 & 76.9 & 23.1 \\
\hline & Placebo & 22 & & 63.6 & 36.4 & 63.6 \\
\hline
\end{tabular}

$\mathrm{NP}=$ not published; pts $=$ patients.

There was a statistically significant difference favoring the drug studied.

${ }^{*} \mathrm{mg} / \mathrm{kg}$ per day. 
ing neuronal excitotoxicity antagonizing glutamatergic actions in the $\mathrm{CNS}^{17}$; it has been hypothesized that it acts similarly to zonisamide, a drug capable of inactivating voltage-gated calcium channels. ${ }^{35}$ The second protective mechanism is related to its anti-inflammatory effect, whereby it acts as an irreversible inhibitor of myeloperoxidase, interferes with neutrophil migration and recruitment, blocks peroxidase activity in eosinophils, and inhibits the generation of 5-lipoxygenase products, reducing the generation of neurotoxic free radicals. Inflammation is very important in the genesis of cerebral vasospasm and in secondary ischemic damage. ${ }^{17,25,35}$ We chose the dapsone dose of $100 \mathrm{mg}$ per day, as we use in clinical practice, because it is well-tolerated and similar doses have demonstrated good blood-brain barrier penetration and CSF levels. ${ }^{29}$

\section{Limitations}

The present work has some limitations, such as it being unknown whether the patients presented with cerebral vasospasm and, thus, if dapsone had protective effects in the brain tissue against the ischemia caused by it, or alternatively, if dapsone avoided or diminished the vasospasm phenomenon. This could be an area to study in a future series of patients undergoing protocolized transcranial Doppler ultrasonography or repeat angiography, as well as cerebral blood flow studies that can be performed during the vasospasm-susceptible period. Another important limitation is that, although the study was carried out in a reference neurosurgical center for aneurysmal $\mathrm{SAH}$, more results must be obtained in other centers that treat similar patients in order to establish a causal relationship. However, our reported results are valid despite these limitations.

\section{Conclusions}

Our study suggests that dapsone might be clinically beneficial in reducing the appearance of DCI, improving the clinical outcome at 3 months, and reducing the incidence of cerebral infarction as detected by CT. In our opinion, this justifies the performance of a multicenter study including physiological measurements of cerebral vasospasm and/or cerebral blood flow, which would increase the number of patients treated and determine the consistency of the results observed in the present trial.

\section{References}

1. Chugh C, Agarwal H. Cerebral vasospasm and delayed cerebral ischemia: review of literature and the management approach. Neurol India. 2019;67(1):185-200.

2. McGirt MJ, Mavropoulos JC, McGirt LY, et al. Leukocytosis as an independent risk factor for cerebral vasospasm following aneurysmal subarachnoid hemorrhage. J Neurosurg. 2003;98(6):1222-1226.

3. Parra A, Kreiter KT, Williams S, et al. Effect of prior statin use on functional outcome and delayed vasospasm after acute aneurysmal subarachnoid hemorrhage: a matched controlled cohort study. Neurosurgery. 2005;56(3):476-484.

4. Tseng MY, Czosnyka M, Richards H, Pickard JD, Kirkpatrick PJ. Effects of acute treatment with pravastatin on cerebral vasospasm, autoregulation, and delayed ischemic deficits after aneurysmal subarachnoid hemorrhage: a phase
II randomized placebo-controlled trial. Stroke. 2005;36(8): 1627-1632.

5. Bøthun ML, Haaland ØA, Moen G, et al. Impaired cerebrovascular reactivity may predict delayed cerebral ischemia after aneurysmal subarachnoid hemorrhage. J Neurol Sci. 2019;407:116539.

6. Ditz C, Leppert J, Neumann A, et al. Cerebral vasospasm after spontaneous subarachnoid hemorrhage: angiographic pattern and its impact on the clinical course. World Neurosurg. 2020;138:e913-e921.

7. Hoh BL, Topcuoglu MA, Singhal AB, et al. Effect of clipping, craniotomy, or intravascular coiling on cerebral vasospasm and patient outcome after aneurysmal subarachnoid hemorrhage. Neurosurgery. 2004;55(4):779-789.

8. Hollingworth M, Jamjoom AAB, Bulters D, Patel HC. How is vasospasm screening using transcranial Doppler associated with delayed cerebral ischemia and outcomes in aneurysmal subarachnoid hemorrhage? Acta Neurochir (Wien). 2019; 161(2):385-392.

9. Keller E, Krayenbühl N, Bjeljac M, Yonekawa Y. Cerebral vasospasm: results of a structured multimodal treatment. Acta Neurochir Suppl. 2005;94:65-73.

10. Claassen J, Bernardini GL, Kreiter K, et al. Effect of cisternal and ventricular blood on risk of delayed cerebral ischemia after subarachnoid hemorrhage: the Fisher scale revisited. Stroke. 2001;32(9):2012-2020.

11. Qureshi AI, Sung GY, Razumovsky AY, Lane K, Straw RN, Ulatowski JA. Early identification of patients at risk for symptomatic vasospasm after aneurysmal subarachnoid hemorrhage. Crit Care Med. 2000;28(4):984-990.

12. Ahn SH, Savarraj JP, Pervez M, et al. The subarachnoid hemorrhage early brain edema score predicts delayed cerebral ischemia and clinical outcomes. Neurosurgery. 2018;83(1): 137-145.

13. Goddard AJ, Raju PP, Gholkar A. Does the method of treatment of acutely ruptured intracranial aneurysms influence the incidence and duration of cerebral vasospasm and clinical outcome? J Neurol Neurosurg Psychiatry. 2004;75(6):868-872.

14. Dasenbrock HH, Rudy RF, Rosalind Lai PM, et al. Cigarette smoking and outcomes after aneurysmal subarachnoid hemorrhage: a nationwide analysis. J Neurosurg. 2018;129(2): 446-457.

15. Ido K, Kurogi R, Kurogi A, et al. Effect of treatment modality and cerebral vasospasm agent on patient outcomes after aneurysmal subarachnoid hemorrhage in the elderly aged 75 years and older. PLoS One. 2020;15(4):e0230953.

16. Inagawa $\mathrm{T}$, Yahara $\mathrm{K}$, Ohbayashi $\mathrm{N}$. Risk factors associated with cerebral vasospasm following aneurysmal subarachnoid hemorrhage. Neurol Med Chir (Tokyo). 2014;54(6):465-473.

17. Ríos C, Nader-Kawachi J, Rodriguez-Payán AJ, Nava-Ruiz C. Neuroprotective effect of dapsone in an occlusive model of focal ischemia in rats. Brain Res. 2004;999(2):212-215.

18. Hosoda K, Fujita S, Kawaguchi T, Shose Y, Hamano S, Iwakura M. Effect of clot removal and surgical manipulation on regional cerebral blood flow and delayed vasospasm in early aneurysm surgery for subarachnoid hemorrhage. Surg Neurol. 1999;51(1):81-88.

19. Thomas JE, Rosenwasser RH, Armonda RA, Harrop J, Mitchell W, Galaria I. Safety of intrathecal sodium nitroprusside for the treatment and prevention of refractory cerebral vasospasm and ischemia in humans. Stroke. 1999;30(7):14091416.

20. Boulouis G, Labeyrie MA, Raymond J, et al. Treatment of cerebral vasospasm following aneurysmal subarachnoid haemorrhage: a systematic review and meta-analysis. Eur Radiol. 2017;27(8):3333-3342.

21. Li K, Barras CD, Chandra RV, et al. A Review of the Management of cerebral vasospasm after aneurysmal subarachnoid hemorrhage. World Neurosurg. 2019;126:513-527. 
22. Patel AP, Patil AS. Dapsone for immune thrombocytopenic purpura in children and adults. Platelets. 2015;26(2):164-167.

23. Porro AM, Hans Filho G, Santi CG. Consensus on the treatment of autoimmune bullous dermatoses: pemphigus vulgaris and pemphigus foliaceus-Brazilian Society of Dermatology. An Bras Dermatol. 2019;94(2)(suppl 1):20-32.

24. Roman C, Dima B, Muyshont L, Schurmans T, Gilliaux O. Indications and efficiency of dapsone in $\operatorname{IgA}$ vasculitis (Henoch-Schonlein purpura): case series and a review of the literature. Eur J Pediatr. 2019;178(8):1275-1281.

25. Suda T, Suzuki Y, Matsui T, et al. Dapsone suppresses human neutrophil superoxide production and elastase release in a calcium-dependent manner. Br J Dermatol. 2005;152(5):887895.

26. Van Malderen C, Van Geertruyden JP, Machevo S, et al. Glucose-6-phosphate dehydrogenase deficiency, chlorproguanil-dapsone with artesunate and post-treatment haemolysis in African children treated for uncomplicated malaria. Malar J. 2012;11:139.

27. López-Naranjo F, Castañeda-López C, Rojas-Oviedo I, et al. Anticonvulsant activity of dapsone analogs. Electrophysiologic evaluation. Arch Med Res. 2003;34(4):269-272.

28. Teasdale GM, Drake CG, Hunt W, et al. A universal subarachnoid hemorrhage scale: report of a committee of the World Federation of Neurosurgical Societies. J Neurol Neurosurg Psychiatry. 1988;51(11):1457.

29. Fisher CM, Kistler JP, Davis JM. Relation of cerebral vasospasm to subarachnoid hemorrhage visualized by computerized tomographic scanning. Neurosurgery. 1980;6(1):1-9.

30. Tatu L, Moulin T, Bogousslavsky J, Duvernoy H. Arterial territories of the human brain: cerebral hemispheres. Neurology. 1998;50(6):1699-1708.

31. Laumer R, Steinmeier R, Gönner F, Vogtmann T, Priem R, Fahlbusch R. Cerebral hemodynamics in subarachnoid hemorrhage evaluated by transcranial Doppler sonography. Part 1. Reliability of flow velocities in clinical management. Neurosurgery. 1993;33(1):1-9.

32. Lewis DH, Newell DW, Winn HR. Delayed ischemia due to cerebral vasospasm occult to transcranial Doppler. An important role for cerebral perfusion SPECT. Clin Nucl Med. 1997;22(4):238-240.

33. Rabinstein AA, Friedman JA, Weigand SD, et al. Predictors of cerebral infarction in aneurysmal subarachnoid hemorrhage. Stroke. 2004;35(8):1862-1866.

34. Shimoda M, Takeuchi M, Tominaga J, Oda S, Kumasaka A, Tsugane R. Asymptomatic versus symptomatic infarcts from vasospasm in patients with subarachnoid hemorrhage: serial magnetic resonance imaging. Neurosurgery. 2001;49(6):13411350 .

35. He J, Zhang X, He W, et al. Neuroprotective effects of zonisamide on cerebral ischemia injury via inhibition of neuronal apoptosis. Braz J Med Biol Res. 2021;54(4):e10498.

36. Mee E, Dorrance D, Lowe D, Neil-Dwyer G. Controlled study of nimodipine in aneurysm patients treated early after subarachnoid hemorrhage. Neurosurgery. 1988;22(3):484491.

37. Ohman J, Heiskanen O. Effect of nimodipine on the outcome of patients after aneurysmal subarachnoid hemorrhage and surgery. J Neurosurg. 1988;69(5):683-686.

38. Petruk KC, West M, Mohr G, et al. Nimodipine treatment in poor-grade aneurysm patients. Results of a multicenter double-blind placebo-controlled trial. J Neurosurg. 1988;68(4): 505-517.
39. Pickard JD, Murray GD, Illingworth R, et al. Effect of oral nimodipine on cerebral infarction and outcome after subarachnoid haemorrhage: British aneurysm nimodipine trial. BMJ. 1989;298(6674):636-642.

40. Asano T, Takakura K, Sano K, et al. Effects of a hydroxyl radical scavenger on delayed ischemic neurological deficits following aneurysmal subarachnoid hemorrhage: results of a multicenter, placebo-controlled double-blind trial. J Neurosurg. 1996;84(5):792-803.

41. Haley EC Jr, Kassell NF, Apperson-Hansen C, Maile MH, Alves WM. A randomized, double-blind, vehicle-controlled trial of tirilazad mesylate in patients with aneurysmal subarachnoid hemorrhage: a cooperative study in North America. J Neurosurg. 1997;86(3):467-474.

42. Zhao J, Zhou D, Guo J, et al. Efficacy and safety of fasudil in patients with subarachnoid hemorrhage: final results of a randomized trial of fasudil versus nimodipine. Neurol Med Chir (Tokyo). 2011;51(10):679-683.

43. Matsuda N, Naraoka M, Ohkuma H, et al. Effect of cilostazol on cerebral vasospasm and outcome in patients with aneurysmal subarachnoid hemorrhage: a randomized, double-blind, placebo-controlled trial. Cerebrovasc Dis. 2016;42(1-2):97105.

44. Chen J, Li M, Zhu X, et al. Atorvastatin reduces cerebral vasospasm and infarction after aneurysmal subarachnoid hemorrhage in elderly Chinese adults. Aging (Albany NY). 2020; 12(3):2939-2951.

\section{Disclosures}

The authors report no conflict of interest concerning the materials or methods used in this study or the findings specified in this paper.

\section{Author Contributions}

Conception and design: all authors. Acquisition of data: Nathal, García-Pastor. Analysis and interpretation of data: all authors. Drafting the article: all authors. Critically revising the article: all authors. Reviewed submitted version of manuscript: all authors. Approved the final version of the manuscript on behalf of all authors: Nathal. Statistical analysis: Tristán-López, Ríos, DíazRuíz, Rodríguez-Hernandez. Administrative/technical/material support: Tristán-López, Ríos, Díaz-Ruíz. Study supervision: Nathal, García-Pastor, Navarro-Garcia de Llano, Balcázar-Padrón, Ríos, Rodríguez-Hernandez.

\section{Supplemental Information}

\section{Previous Presentations}

Portions of this work were presented in abstract form at the 2007 International Stroke Conference, San Francisco, California, February $7-9,2007$.

\section{Correspondence}

Edgar Nathal: Instituto Nacional de Neurología y Neurocirugía "Manuel Velasco Suárez", Mexico City, Mexico. enathal@yahoo. com. 